\title{
ETOS GERAKAN DAN STRATEGI AKSI MUHAMMADIYAH MENYAMBUT MUKTAMAR KE 48 DI SOLO, JAWA TENGAH
}

\author{
Nurbani Yusuf
}

\begin{abstract}
Abstrak
Semarak Muktamar Muhammadiyah ke-48 yang akan diselenggarakan di Kota Solo seolah menjadi wahana untuk para kader berlomba-lomba memberikan kontribusinya guna kemajuan umat dan bangsa. Tulisan ini merupakan sebuah upaya konkrit yang dilakukan oleh penulis untuk meningkatkan etos gerakan dan strategi aksi Muhammadiyah dalam menghadapi tantangan zaman. Muhammadiyah bukan saja gerakan pemikiran tapi juga sekaligus gerakan amal, yang dikemas dalam satu pergerakan yang dinamis dan utuh dengan tidak meninggalkan watak ke-Islamannya, Carl Whiterington menyebut bahwa sebagai sebuah harakah pemikiran, Muhammadiyah menawarkan gagasan modernisasi, purifikasi dan moderasi yang komplet.
\end{abstract}

Kata Kunci: Etos Gerakan, Strategi Aksi, Muhammadiyah, Muktamar Ke-48 Muhammadiyah

\section{Tajdid Al Harakah}

Muhammadiyah menabalkan dirinya sebagai pergerakan Islam paling menginspirasi selama satu abad terakhir, 'perkoempoelan' yang digagas oleh Kyai Ahmad Dahlan ini bahkan telah melampaui pergerakan Islam yang duluan lahir di negeri Timur Tengah, Mesir, Pakistan dan pesisir India dan 
Yaman. Sebut saja Pan Islamisme Syaikh Afghan, gerakan purifikasi Syaikh Abdul Wahab, Ali Jinah, Iqbal atau al Maoudodi di India dan Pakistan, atau gerakan salafi Syaikh Abduh dan muridnya Syaikh Rasyid Ridha di Mesir, atau gerakan-gerakan politik. Ikhwan-nya Syaikh al Banna, HT-nya Syaikh Taqiyuddin an Nabhani, atau gerakan kultural sufiistik semisal Syaikh at Tijani, Syaikh Naqsabandy, hampir semua yang saya sebut tidak pernah menjadi besar di negerinya sendiri bahkan ada yang kemudian diusir karena tidak sejalan, dengan tidak bermaksud saling merendahkan satu sama lainnya semata hanya semacam komparasi dengan berbagai tipologi dan karakter pergerakan. Tak urung Carl Whiterington menyebut bahwa Muhammadiyah adalah organisasi yang diberkati. (Sajad, 2010).

Muhammadiyah bukan saja gerakan pemikiran tapi juga sekaligus gerakan amal, yang dikemas dalam satu pergerakan yang dinamis dan utuh dengan tidak meninggalkan watak ke-Islamannya, Carl Whiterington menyebut bahwa sebagai sebuah harakah pemikiran, Muhammadiyah menawarkan gagasan modernisasi, purifikasi dan moderasi yang komplet. Tiga pilar ini menjadi pisau yang ampuh untuk membuka cara pandang dan mengubah paradigma umat Islam yang jumud, tertutup dan taqlid menjadi terbuka dan dinamis. Muhammadiyah yang digagas Kyai Dahlan mengembalikan kemuliaan dan harkat Islam yang sempat terpuruk. Kyai Dahlan bukan saja seorang ulama tapi juga seorang pragmatikus agama dalam arti positif, yang handal dan piawai menjalankan firman-firman Tuhan ke dalam bahasa yang dimengerti, sederhana tapi modern dan dibutuhkan masyarakat tempat di mana ia tinggal. Islam aplikatif dan kontekstual. Berbagai amal usaha lahir dari buah pikirnya yang inovatif dan melampaui zamannya. Muhammadiyah adalah organisasi yang diberkati, demikian tulis Whiterington dalam sebuah hasil risetnya yang menarik tentang pergerakan Muhammadiyah.

Gerakan amal Muhammadiyah juga telah menebar di seluruh pelosok tanah air dengan tidak membatasi pada sekat agama, ras atau bahasa. Muhammadiyah telah melampaui semua itu dan hadir ketika negara masih faqir. Modernisasi menjadi salah satu ciri yang lekat, tak ada yang bisa memisahkan Muhammadiyah sebagai gerakan ke-Islaman, kemodernan dan ke-Indonesiaan, tiga paradigma yang digagas Kyai Dahlan di awal berdiri telah mengubah mainstream pergerakan Islam global. Dr Alfian Ketua LIPI menyebutkan dalam Islamic Modernis in Indonesian Politics, the Muhammadiyah Movement during the Dutch Colonial Period 1912-1942 (1989) menyebutkan bahwa Muhammadiyah merupakan gerakan non politik tapi berpengaruh besar terhadap kehidupan berpolitik, 
keterlibatannya berbeda dengan organisasi lain yang menjadikan politik sebagai titik tuju. Tapi di situlah menjadi kelebihannya di banding organisasi politik sekalipun, pengaruh dan daya resonansinya sangat kuat di kalangan politisi saat itu. Dengan begitu Muhammadiyah aman dan jauh dari interst politik kekuasaan. Sebagai organisasi non politik, Muhammadiyah memang tidak selamanya berada di dalam pusat kekuasaan dan tak perlu berharap memanen kerja politik praktis yang riuh tapi sepi aksi. (Alfian, 1989).

Muhammadiyah memiliki etos gerakan yang spesifik dan barangkali berbeda dengan pergerakan lain sejenis, sudahlah jamak bahwa ulama-ulama Muhammadiyah sudah teruji baik materi maupun non materi, mereka adalah orang-orang yang sederhana dan tulus berpikir, bukannya menafikan ulama lain tapi secara personal dan institusional Muhammadiyah jelas-jelas yang paling steril dari kepentingan politik kekuasaan juga tidak pernah menghamba pada kepentingan politik aliran tertentu dengan menjual umat untuk kepentingan sesaat.

Lahir jauh sebelum Indonesia merdeka, tepatnya tahun 1912 atau 33 tahun lebih tua dari berdirinya republik. Muhammadiyah telah menunjukkan dasardasar negara modern dengan membangun pendidikan: sekolah, rumah sakit, dan layanan publik lainnya yang kelak menjadi model. Yang memproklamasikan negara ini kader Muhammadiyah, yang rela menghapus tujuh kata pada sila pertama Piagam Jakarta demi kesatuan bangsa juga kader Muhammadiyah, yang paling berani dan konsisten melawan ideologi komunis hingga diancam bubar juga Muhammadiyah, bapak pembangunan juga bibit Muhammadiyah dan sederet prestasi lainnya dan semua lahir pada saat negara dalam keadaan hilang haluan. Bersyukur pula selalu diberi pemimpin yang tepat pada saat yang tepat, gaduh azas tunggal Pancasila ada Pak AR Fakhruddin yang bijak dan teduh, geliat reformasi ada Pak Amien Rais yang lugas dan berani, gaduh soal politik identitas ada Pak Haidar Nashir yang santun. Dari berbagai karakter para pemimpin di persyarikatan ini kemudian menjadi simbol gerakan. Peran Muhammadiyah tidaklah gampang dihilangkan. Bahkan secara institusional para pemimpin Muhammadiah relatif bersih dan tidak ada yang tersandung pada perilaku koruptif, amoral atau tindakan makar lainnya meski sama-sama telah menempati posisi di pemerintahan pusat maupun daerah, berbeda dengan ormas atau partai lainnya yang sama-sama mengaku memperjuangkan Islam. 
Realitas ini yang memperkokoh posisi dan peran Muhammadiyah sangat diperhitungkan meski dalam beberapa kasus Muhammadiyah diidentikkan dengan sikap agak kaku dan sedikit 'sombong' karena sulit diajak kompromi. Keseluruhan, inilah persyarikatan modern dengan tampilan bersahaja. Meski modern tetap mengedepankan kebersamaan dan urunan gaya ndeso, bahkan banyak amal usaha yang dikelola amat sederhana tetapi eksis.

\section{Kebermaknaan Etos dalam Pergerakan}

Diskursus masalah etos kerja telah menjadi bahan bincang menarik di sebagian besar masyarakat kita, pembicaraan itu tidak jarang dalam suasana pesismis dan kuwatir bahwa sebagai bangsa kita bisa saja gagal menumbuhkan etos kerja yang baik dan berkualitas. Maka kemungkinan kita bakal tetap tertinggal dari bangsa-bangsa lain, berbagai prediksi menyebutkan bahwa negara kita bisa saja menjadi back yard atau halaman belakang dari bangsa bangsa sekitar. Sebuah pembahasan pernah diangkat dalam sebuah diskusi seru pada sebuah majalah Reader Digest, bangsa kita memang sedang menderita lemah etos kerja akut. Selanjutnya dikatakan bahwa bangsa kita sedang mengidap indonesia has lousy work ethic and serious corruption (Indonesia mempunyai etika kerja yang cacat dan korupsi yang gawat), pernyataan paling pesimis dan bisa saja kemudian menjadi semacam ancaman nyata dalam kehidupan berbangsa dan negara. Etos kerja yang rendah dan perilaku koruptif akan menjadi penghalang bagi pemajuan dan pemodernan, hal mana harus dibuktikan bahwa tak sepenuhnya demikian. (Kraar, 1988).

Pengertian kamus bagi perkataan etos menyebutkan bahwa ia berasal bahasa Yunani Etos yang bermakna watak atau karakter. Maka secara lengkapnya etos ialah karakteristik dan sikap kebiasaan serta kepercayaan dan seterusnya yang bersifat khusus tentang seorang individu atau sekelompok manusia. Dari kata etos terambil pula perkataan etika dan etis yang merujuk kepada makna akhlaq atau bersifat akhlaqi yaitu kualitas seseorang atau sekelompok manusia atau suatu bangsa. Juga dikatakan bahwa etos berarti jiwa khas suatu kelompok manusia yang dari jiwa khas itu berkembang pandangan bangsa tersebut tentang yang baik dan yang buruk yakni etikanya. (Sohari, 2013).

Dalam pengertian itu maka negara-negara industri baru NICs Newly Industrializing Countries di sekitaran Indonesia, Korea Selatan, Taiwan, Hongkong dan Singapura seringkali disebut little dragons. Mereka adalah 
negara- negara penganut konfusianis penganut ajaran Konghucu dengan ular naga sebagai binatang mitologis dalam sistem kepercayaan mereka, anggapan lain menyebutkan bahwa dengan pandangan yang hampir memastikan bahwa negara negara itu maju karena ajaran failasuf China itu. Selanjutnya dibuat kesimpulam bahwa etika konghucu memang relevan, bahkan mendukung bagi usaha-usaha modernisasi dan pemajuan bangsa industrial, cara pandang serupa itu sebenarnya merupakan penerapan weberisme dalam etika protestan di luar Eropa Barat seperti banyak dilakukan para ahli (Fong \& Haggard, 1992).

Tidak dipungkiri lagi China sebagai negara dengan penduduk terbesar di dunia telah menjelma menjadi raksasa baru melampaui banyak negara Asia dan Eropa-China bukan saja menang dalam industri tapi juga raksasa baru dalam hal sumber daya manusia yang ulet rajin dan produktif dengan biaya murah. China telah mengubah dirinya sejajar dengan negara negara Eropa Barat dan Amerika yang lebih maju dan modern.

\section{Tradisi Tajdid dan Pembaharuan Sebagai Sumber Etik}

Pandangan Islam mengenai etos kerja bisa dimulai dari usaha menangkap makna substantif sabda Nabi saw yang amat terkenal bahwa nilai setiap bentuk kerja itu tergantung niat yang melekat pada pelakunya, jika tujuannya tinggi seperti mencapai ridha Allah maka iapun akan mendapatkan nilai kerja yang tinggi dan jika tujuannya rendah seperti ingin mencapai simpati sesama manusia belaka maka setingkat tujuan itu pulalah nilai kerjanya tersebut. (Thaib, 2014) selain mencari rezeki namun juga cita-cita. Dalam bekerja diwajibkan memilih pekerjaan yang baik dan halal, karena tidak semua pekerjaan itu diridhai Allah SWT. Etos kerja yang sehat akan mendorong seseorang bekerja keras, menambah wawasan, mempertajam skill serta mewarnai etos kerjanya dengan nilai-nilai Islam. Bekerja bagi seorang muslim adalah suatu upaya yang sungguhsungguh, dengan menggerakkan seluruh aset, pikiran dan zikirnya untuk mengaktualisasikan atau menampakkan arti dirinya sebagai hamba Allah yang harus menundukkan dunia dan menempatkan dirinya sebagai bagian dari masyarakat yang terbaik (khairul ummah).

Sabda Nabi saw menegaskan bahwa tinggi rendah nilai kerja seseorang bergantung pada niat masing masing, sesuai komitmen yang dimilikinya, bentuk pilihan dan keputusan pribadi yang dikaitkan dengan sistem nilai (value sistem) yang dianutnya, oleh karena itu niat bisa menjadi sumber etik yang pertama dan 
terpenting, sebagai daya dorong bagi seseorang atau sekelompok manusia untuk melakukan atau tidak melakukan sesuatu. Sabda Nabi saw juga diisyaratkan bahwa seorang Muslim harus bekerja dengan niat memperoleh ridha Allah dan Rasul-Nya, sudah barang tentu ini amat standart dalam agama Islam. Bahwa kualitas pekerjaan seseorang bergantung pada niat dan komimtmen pelakunya tergambar pada pesan Tuhan agar tidak membatalkan amal kebajikan dengan ungkapan yang menyakitkan atau umpatan, sebagai indikasinya tiadanya niat dan komitmen yang tinggi, yang dalam bahasa agama disimpulkan sebagai komitmen kepada ridha Allah swt:

"Wahai sekalian orang orang yang beriman, janganlah kamu membatalkan sedekah sedekahmu dengan umpatan menyebut pemberian pemberian itu dan sikap menyakitkan hati, seperti orang yang mendermakan hartanya secara pamrih kepada manusia tanpa ia beriman kepada Allah dan hari akhirat. Perumpamaan orang itu adalah bagaikan batu besar yang keras yang di atasnya ada sedikit debu, kemudian ditimpa hujan lebat dan batu itu ditinggalkan tanpa apa apa, orang orang serupa itu tidak akan berbuat sesuatu tanpa dengan apa yang telah mereka lakukan. Dan Allah tidak akan memberi petunjuk kepada kaum yang ingkar". (al-Baqarah: 264)

Jadi apapun yang kita lakukan jika niatnya salah bukan karena mencari ridha Allah dan Rasul-Nya maka semua amal kebajikan yang dilakukan tidak mendapatkan penghargaan sama sekali karena niat dan komitmennya yang rendah. Bergandengan dengan itu patut pula kita renungkan makna firman Allah yang kita renungkan yang memberi ilustrasi tentang kualitas kaum beriman:

\footnotetext{
"Mereka orang orang baik (abrar) karena cinta kepada-Nya untuk orang miskin, anak yatim dan orang terbelenggu. Mereka berkata kami memberi makan kepadamu ini adalah tidak lain demi wajah ridha Allah semata, dan kami tidak menghendaki balasan atau pun ucapan terimakasih dari kamu”, (Qs: al-Insan;76)
}

Pesan pesan Tuhan itu jelas merupakan perlunya menjaga niat dan komitmen agar semua pekerjaan yang dilakukan mendapatkan penghargaan karena berkualitas tinggi. Semua pekerjaan yang tidak berniat dan berkomitmen kepada ridha Allah swt bagaikan fatamorgana atau hanya debu di atas batu yang 
tertimpa hujan, hilang tiada bekas sama sekali. Jadi pekerjaan tanpa tujuan luhur mengalami kehampaan, percuma tiada berguna, tidak memberi manfaat dan kebahagian kepada pelakunya.

\section{Ihsan Sebagai Etos Gerakan}

Melakukan kebajikan atau amal baik dengan niat mencari ridha Allah berimplikasi tidak boleh dikerjakan sembrono atau asal asalan-tapi harus serius sungguh-sungguh sebagai bentuk komitmen yang tulus lagi kokoh. BerMuhammadiyah tak boleh sambilan hanya di sisa waktu, dikerjakan secara acuh tak acuh. Sebab hal itu akan membatalkan niat bersungguh-sungguh mencari ridha Allah, niatnya menjadi absurd karena tanpa kesejatian dan kesungguhan. (Jinan, 2015).

Berkaitan dengan masalah niat dan komitmen pergerakan sebagai upaya optimalisasi nilai dan hasil kerja maka sangat relevan dengan ajaran tentang ihsan, makna ihsan itu luas sekali, antara lain yang langsung relevan dengan masalah etos gerakan kita adalah perbuatan terbaik dalam pengertian sebaik mungkin atau seoptimal mungkin. Misalnya diilustrasikan dalam sebuah hadits sahih riwayat Muslim yang menuturkan sabda Nabi saw:

"Sesungguhnya Allah mewajibkan ihsan atas segala sesuatu. Karena itu jika kamu membunuh maka berihsanlah dalam membunuh itu dan jika kamu menyembelih maka berihsanlah dalam menyembelih itu, dan hendaknya seseorang menajamkan pisaunya dan menenangkan binatang sembelihannya itu”. Mukhtashar:36-29

Bahwa Allah mewajibkan ihsan atas segala sesuatu, ditegaskan dalam kitab suci bahwa Allah yang membuat baik, sebaik-baiknya melaksanakan ihsan atas segala sesuatu yang diciptakannya, kemudian di samping ihsan juga digunakan ungkapan lain yaitu itqan yang artinya kurang lebih ialah membuat atau mengerjakan sesuatu secara sungguh sungguh teliti, sehingga rapi, indah, tertib harmoni bersesuaian antara satu dengan yang lain. Maka disebut bahwa seluruh alam ini adalah seni ciptaan Allah yang menciptakan dengan teliti at-qana melaksanakan itqan segala sesuatu-dalam bahasa populer, firman firman itu menunjukkan bahwa Allah tidak pernah bersikap setengah-setengah, mediocre separuh hati dalam menciptakan segala sesuatu. 
Selanjutnya disebutkan bahwa Allah juga telah melakukan ihsan terhadap manusia kemudian dituntut agar manusia melakukan ihsan. Dalam kaitan ini amat menarik bahwa perintah Allah agar kita melakukan ihsan dikaitkan peringatan agar kita mengusahakan tercapainya kebahagiaan di akhirat melalui penggunaan yang benar akan harta dan karunia Allah kepada kita namun janganlah kita melupakan bagian nasib kita di dunia ini.

"Dan usahankanlah dalam karunia yang telah diberikan Allah kepadamu itu kebahagiaan negeri akhirat, namun janganlah engkau lupa akan nasibmu dari dunia ini, serta lakukanlah ihsan sebagaimana allah telah melakukan ihsan kepadamu dan janganlah kamu membuat kerusakan di bumi. Sesungguhnya Allah tidak suka dengan orang orang yang membuat kerusakan." (al Qashas:77).

Ayat ini menegaskan bahwa dalam ber-Muhammadiyah harus sungguh-sungguh dan menyempurnakan kesungguhannya itu dalam bentuk amal saleh yang tulus mencari ridha Allah dan Rasul-Nya. Para foundhing-father kita telah memberi banyak keteladanan kesungguhan menegakkan amar maruf nahy munkar-Kyai Ahmad Dahlan adalah uswah terbaik bagaimana memahami ke-Islaman dan keIndonesiaan dalam sebuah bingkai yang utuh yang kemudian diwujudkan dalam bentuk gerakan kemanusiaan. Kyai Ahmad Dahlan telah dengan cerdas berhasil memadukan antara gerakan pemikiran dan gerakan amal secara berimbang. Ihsan yang dijadikan model oleh Kyai Dahlan di awal pergerakan telah banyak memberi inspisrasi bagi gerakan permodernan dan pemajuan Islam secara holistik. Islam rahmatan lil alamin, Islam wasathiyah. (Fitri, 2015).

Dengan ihsan itulah kita ber-Muhamamadiyah bersungguh-sungguh untuk meraih masa depan dengan tujuan-tujuan yang lebih tinggi. Beruntung di dunia dan di akhirat-gabungan keduanya itu kemudian dikaitkan dengan sikap ihsan yaitu menjalani sikap hidup dengan kesungguhan untuk mendapat kesempurnaan.

\section{Strategi dan Aksi Muhammadiyah Menyambut Muktamar}

Sudah tidak diragukan lagi bahwa Muhammadiyah adalah gerakan amal dengan ribuan amal usaha mulai pendidikan, rumah sakit, bait amal, panti asuhan dengan jumlah mencapai ribuan adalah bukti bahwa gerakan ini dekat dengan massa rakyat berbasis kebutuhan, bahkan sudah hadir ketika negara masih dalam 
keadaan faqir, kontribusi besar ini tak cukup dipandang enteng. Sebab bukan hanya soal berapa jumlah amal usahanya, tapi Muhammadiyah juga berperan besar dalam menumbuhkan partisipasi publik, membangun demokrasi sosial dan politik. Sebab itulah tidak terlalu mengherankan jika kemudian menjelma menjadi sebuah holding amal usaha yang meraksasa sebagai simbol pegerakan, meski kemudian dirasa pincang sebab tumbuh suburnya amal usaha tidak dibarengi dengan tumbuhnya gerakan pemikiran modernis, sebagai simbol pembaharuan.

Ada ketimpangan pemikiran di persyarikatan ini selama kurang lebih dua atau tiga dasa warsa terakhir, lembaga pemikiran sekelas Majelis Tarjih kalah prestise di banding dengan pendirian TK atau PAUD-sebagian besar kita bangga dengan amal usaha tapi tidak pada hasil pemikiran terbarukan, bahkan menurut Boy (2016), justru di Muhammadiyah sangat sulit berkembang pikiran plural dan gampang menyebut stigma liberal, sekuler, munafiq dan lainnya untuk setiap yang kebetulan berbeda pendapat, tradisi berpikir plural di Muhammadiyah sangat lemah dan miskin perbedaan. Padahal 'perkoempoelan' ini lahir dan dibesarkan oleh pikiran modern, berbeda dan berani melawan kemapanan. Ironi di tengah 'perkoempoelan' yang mengaku berkemajuan perbedaan pendapat mengalami mati suri, olah nalar dan olah pikir tidak mendapat penghormatan sepadan.

Kyai Ahmad Dahlan adalah pintu masuk memahamai pikiran dan gagasan ke Muhammadiyahan, mestinya menjadi satu-satunya rujukan dalam hal mengenal dan memahamai model pola pikir keberagamaan agar tak jauh menyimpang, sebagai ihtiar menjaga originalitas dan otentisitas pergerakan, dengan amat berani saya menyatakan bahwa dalam diri Kyai Besar Ahmad Dahlan ada tradisi berpikir liberal (dalam pengertian tajdid anti tesis terhadap kondisi kaumnya) dan berpikir puritan sekaligus. Dalam buku Muhammadiyah di penghujung abad 20 kumpulan makalah menjelang Muktamar Solo, disebutkan ketika Kyai Dahlan oleh salah seorang muridnya di OSVIA Soegarda Poerbakawatja (yang kemudian menjadi konseptor dan penggagas berbagai perguruan tinggi negeri: UGM, UI termasuk FKIP Muhammadiyah) Kyai Dahlan membolehkan mengganti bacaan shalat dengan bahasa yang dimengerti. Jawaban cukup berani mengingat kondisi psikolgis umat Islam saat itu yang benar-benar jumud dan terpuruk oleh tradisi dan kooptasi Belanda akibat pembodohan struktural kompeni yang menjauhkan umat Islam dari al-Qur'an sehingga banyak orang membaca tapi tak mengerti isinya, maka Kyai Dahlan pun membolehkan menterjemahkan al-Qur'an ke dalam bahasa lokal meski dilawan dan di tentang habis oleh kyai lokal saat itu. Dengan amat serius Prof Malik Fadjar dalam 
sebuah diksi menyatakan, "bawalah Muhammadiyah ke ruang terang dan jangan bawa ke tempat gelap dan lorong sempit." ( Ni'mah, 2014).

Menyisir dua tradisi berpikir tajdid yang cenderung bebas modern dan puritan yang tekstual konservatif tidaklah sulit. Keduanya ada dan dipraktikkan secara simultan dan bersamaan sebagai sebuah paradigma berpikir yang hidup dan tumbuh di pergerakan Muhammadiyah yang digagas Kyai Ahmad Dahlan. Prof Yunahar Ilyas (1993) menyatakan bahwa salah satu manhaj Muhammadiyah tidak liberal dan tidak puritan. Secara eksplisit menyatakan bahwa tradisi berpikir liberal dan puritan memang nyata ada, karenanya keduanya harus diseimbangkan agar tak berebut dominan. Meski sulit dirumuskan dalam bentuk konseptual praksis. Memberi ilustrasi bahwa dua model berpikir itu memang tumbuh dan berkembang karenanya tidak harus saling menafikkan. Tegasnya, Muhammadiyah memposisikan diri sebagai Islam moderat atau wasathiyah. Muhammadiyah tidak liberal juga tidak radikal. Memegang teguh prinsip tawasuth, tawazun, dan ta'adul.

Tradisi berpikir tajdid di awal pergerakan cukup dominan dan berpengaruh signifikan terhadap ruh pemikiran Kyai Ahmad Dahlan ke depan. Praktik berpikir tajdid inilah yang memberi warna pergerakan pemikiran Muhammadiyah yang oleh Prof Din Syamsudin disebut sebagai federasi pemikiran dan gagasan modernis. Kyai Dahlan bahkan sering menabrak tabu. Sering disebut kyai londo atau kyai kafir karena banyak meniru kompeni dalam hal amal usaha yang dibangunnya berupa sekolah dan sistem pengajarannya. Jika tajdid dimaknai sebagai cara berpikir bebas dan modern maka Kyai Dahlan adalah orangnya. Model sekolah dikembangkannya adalah mirip sekolah paroki, menulis dengan huruf latin, mengajarkan ilmu kafir (ilmu hitung, alam dan seni) menggunakan sistem klasikal, menterjemahkan al-Qur'an, adalah bukti bahwa Kyai Ahmad Dahlan berani melawan fiqh mapan, menabrak kelaziman, antitesis bagi kaumnya yang beku dan jumud berpikir, Carl Whiterington menyebutnya sebagai seorang pragmatikus agama yang inovatif dan kreatif. Tak urung Abdurahman Wahid atau Gus Dur menyebut kemenangan Muhammadiyah atas NU adalah kemenangan dialektik yang awalnya dibantah kemudian dibenarkan dan ditiru ramairamai, semua yang telah dilakukan Muhammadiyah sekarang dilakukan NU tanpa kecuali. (Ilyas et al., 1993). 
Tradisi puritan juga tak kalah dominan. Dengan jargon kembali kepada alQur'an dan as-Sunnah, Muhammadiyah adalah sebuah gerakan pemurnian yang berpengaruh mendobrak kemapanan dan kejumudan umat Islam saat itu. Ruang gerak Kyai Dahlan melakukan purifikasi juga tak kalah heboh, banyak mendapat simpati sekaligus perlawanan dari para ulama. Gagasan meluruskan arah kiblat cukup membuat repot para ulama, belum lagi kukuhnya melawan tahayul, bid'ah dan khurafat dan tradisi Jawa yang mengandung banyak kesyirikan. Puritanisme yang digagas Kyai Dahlan dekat dengan pikiran Syaikh Muhammad Abduh dan muridnya Syaikh Muhammad Rasyid Ridha dan persinggungannya dengan majalah al-Urwastul Wustqa, menjadi bagian penting yang mempengaruhi pikiran purifikasinya. Kyai Dahlan juga seorang panganjur manhaj salaf-al Islamu mahjubun bil muslimin, menjadi spirit yang penting dalam gerakan pemurnian yang dilakukannya.

Ke depan, menyeimbangkan dua arus besar pemikiran di persyarikatan ini tidaklah mudah, berbagai kecenderungan mengemuka baik secara personal maupun kelompok atau komunitas, ada yang dominan tajdidnya dan adapula yang dominan puritannya, Prof. Syafii Maarif pernah menggagas tentang Muhammadiyah sebagai tenda besar bagi setiap manhaj, aliran pemikiran dan semacamnya dengan tidak menafikkan keberadaan Muhammadiyah sebagai gerakan yang bertumpu pada amar maruf nahy munkar. Memang, tak mudah memadukan dua arus utama pemikiran dalam satu kesatuan gerak, tetap saja ada yang ingin berebut dominan, yang kemudian tercermin dalam sikap kepolitikan warga dan elite Muhammadiyah dalam menyikapi Pilpres secara keseluruhan menampilkan apakah pikiran tajdid atau puritan yang dominan. Ahmad Najib Burhani menyebut bahwa identitas Muhammadiyah sebagai perpaduan antara purifikasi (Islam murni) dan Islam berkemajuan. Frasa Islam berkemajuan yang mengemuka pada muktamar Makasar menurut penelusuran Najib Burhani adalah kelanjutan penegasan komitmen historis Muhammadiyah pada awal perkembangannya.

Pernyataan Prof Haidar Nashir (2016) bahwa, "Muslim yang baik adalah muslim yang berilmu dan berkontribusi positif bagi kehidupan masyarakat. Bukan yang sedikit-sedikit meneriakkan allahu akbar. Untuk sesuatu yang sebenarnya sangat politis bukannya religius", memiliki makna yang sangat mendalam di tengah euphoria politik identitas dan ghirah jihad dalam arti sempit. Tak diduga bagaimana jika warga Muhammadiyah justru yang paling terdampak oleh pengaruh buruk politik identitas ? 'Perkoempoelan' yang sebelumnya dikenal amat hati-hati dalam berpolitik justru menjadi yang 
paling terimbas oleh jargon-jargon politik identitas yang dibangun oleh FPI dan HTI, bahkan dirasa lambat siuman ketika FPI dan HTI sudah berbenah.

Dari penguatan ide, gagasan dan pikiran-pikiran strategis di atas sudah selayaknya ke depan Muhammadiyah menyiapkan diri menyambut era baru yang lebih dinamis, simple dan efisien, kuat daya fisik berupa amal usaha dan kokoh dalam daya nalar berupa manhaj dan ideologi yang jelas dan terus terbarukan untuk menjaga spirit pergerakan. Maka perlu dilakukan penataan dan aksi-aksi untuk memediasi menjadi pegerakan yang kokoh. Membangun tradisi pemikiran, menggali spirit pergerakan dan meneguhkan kembali tradisi ke-Islaman dalam sebuah pergerakan yang konkret dan nyata, dalam hal ini saya pribadi cenderung memperkokoh serta membaharukan pemikiran dan meneguhkan kembali pikiran-pikiran para foundhing father di awal pergerakan dihidupkan kembali. Jainuri (2004) menyebutkan bahwa purifikasi ditujukan pada aspek Islam yang tak bisa diubah. Sedangkan berkemajuan adalah dinamisasi dalam hal muamalah merupakan area yang bisa berubah menurut waktu, ruang dan kemaslahatan publik. Jadi para ruang yang tidak bisa berubah (aqidah dan Ibadah Mahdhah) Muhammadiyah menempuh jalan purifikasi, sedang pada area yang bisa berubah (muamalah) menempuh jalan pemajuan dan modernisasi. Dalam aspek ubudiyah cenderung puritan dan pada muamalah cenderung dinamis dalam makna pemodernan dan pemajuan.

\section{Membangun Tradisi Sufistik}

Ada anggapan bahwa Muhammadiyah itu gerakan Islam tanpa tarekat. Tradisi purifikasi mau tidak mau telah memposisikan Muhammadiyah berhadap-hadapan dengan tarekat yang dianggap banyak memproduk amalan bid'ah, khurafat dan tahayul hal mana menjadi musuh atau sasaran target dakwah Muhammadiyah, tapi benarkah Muhammadiyah anti tarekat dan membuangnya jauh dalam pikiran dan bangunan keberagamaannya, memang belum ada studi khusus tentang persinggungan pergerakan purifikasi ini dengan tarekat, setidaknya Buya Hamka ingin menunjukkan bahwa berMuhammadiyah tidak harus meninggalkan tarekat.

Ikhtiar Buya HAMKA untuk mengenalkan tradisi sufistik di kalangan santri Muhammadiyah tampaknya kurang mendapat respon bahkan dalam beberapa kurun terakhir cenderung kian ke kanan dengan pendekatan tekstual ala 
Salafi dan Wahabi yang kian mengental. Proses pembentukan watak dan karakter keberagamaan manhaj memang tak pernah final dan memang begitulah seharusnya. Pendekatan tarjih dalam hal ini: Bayani, Irfani, Burhani memang memenuhi syarat minimal tapi belum mencukupi sebab tradisi keberagama-an tak cukup hanya bersandar pada tiga trisula meski secara global diilustrasikan pada jargon kembali pada al-Qur'an dan as-Sunnah. Sebuah jargon yang tidak saja diklaim hanya milik Persyarikatan. Wahabi dan Salafi juga sama ironisnya kesamaan jargon ini di tataran akar rumput kerap terjadi anomali ideologi bahkan penyamaran dalam berbagai aspek.

Yang kemudian dilihat adalah Muhammadiyah dikenal tak ramah dengan tradisi sufistik meski secara personal ada beberapa pengamal secara personal yang tak di ekspose--para pengamal dzikir pagi dan petang, puasa putih (Yawm Albid) adalah bukti kerinduan jamaah Persyarikatan terhadap tradisi sufistik meski dalam tradisi sufistik cara demikian (berdizikir tanpa mursyid) justru dipersalahkan.

Pada sisi lain, ulama-ulama Muhammadiyah di awal pergerakan justru lekat dengan tradisi sufi sebut saja: Kyai Ahmad Dahlan, Kyai Moh Fakhruddin, Kyai Bagus Hadikoesoemo, Kyai Abdurahim Nur dan para ulama mutakhir semisal Buya Syafii Maarif, Prof Amin Abdullah, Prof Malik Fadjar, Prof Imam Suprayogo dan beberapa ulama Muhammadiyah lainnya yang tak bisa disebut. Meski bagi sebagian jamaah, tradisi sufi ini masih asing dan sebagian malah takut dan menghindar dengan alasan bid'ah. Generalisasi takhayul, bid'ah dan khurafat telah menghilangkan makna generiknya dan kehilangan orisinalitas. Cenderung tekstual dan hanya melawan kemapanan tanpa tawaran model. Hal mana justru mengaburkan tradisi santri berbasis jam'iyah pada tataran yang substantif.

Lantas tradisi keberagamaan macam apa yang bakal dikembangkan? Pertanyaan menarik di tengah ghirah melawan TBC. Sayangnya belum ada model baku yang diidealkan sehingga karena belum adanya model yang rigid itu banyak warga Muhammadiyah kemudian bisa dengan mudah menerima paham Wahabi atau Salafi menjadi bagian pergerakan keberagamaan. Kenapa demikian? Jawabnya pendek: Muhammadiyah belum punya model yang dibakukan meski kemudian bisa dialihkan secara rasional, bahwa sebab tiadanya model itulah yang menguatkan tradisi kemodernan dan keterbukaan Muhammadiyah. 
Apakah kemudian boleh dikatakan bahwa dalam Tauhid menganut paham Wahabi--dalam Fiqh dan Mua'malah menganut paham Salafi? Tak ada yang menolak meski tak semua menerima. Mungkin semacam tawaqquf untuk mencuatkan pikiran nyaman di tengah sengkarut manhaj. Sampai tahapan ini saya belum pernah menemukan kajian atau riset dari para ulama Muhammadiyah yang representatif untuk membangun model manhaj Muhammadiyah sebagai ijma kecuali potongan-potongan ide dan gagasan parsial. Kerja Pergerakan memang tak hanya sekedar urunan atau sibuknya rapat pengurus tapi lupa pada yang esensi bahwa Muhammadiyah adalah gerakan tajdid.

\section{Menyusur Tradisi Santri: Studi Singkat Kyai Mas Mansoer Ndresmo}

Ada pergeseran elite Muhammadiyah dari yang semula berbasis pesantren bergeser ke kampus, dari yang semula para pedagang dan saudagar bergeser ke pegawai karyawan, dari yang semula para kyai bergeser ke para guru besar dan cendekiawan alumni perguruan tinggi, hal mana tentu sangat berpengaruh terhadap corak pemikiran dan tradisi yang dibangunnya. Haikal (1993). Kyai Mas Mansoer, salah satu ulama Muhammadiyah yang masih kokoh menjaga tradisi pesantren di tengah arus perubahan dan transisi yang berlangsung cepat di Muhammadiyah, ada baiknya saya ungkap kembali untuk melakukan komparasi dan syukur menumbuhkan kembali tradisi pesantren di Muhammadiyah yang menghilang atau sengaja dihilangkan jejaknya, sejak dua atau tiga dasa warsa terakhir. Setelah tidak diberi makan selama enam bulan di sel tahanan kecuali air. Kyai Mas Mansoer wafat dibunuh oleh tentara Jepang pada usia 49 tahun di tahanan Kali Sosok Surabaya, demikian dituturkan oleh salah seorang cucunya Ibu Nyai Fatimah Zahra binti Kiai Mas Muhajir ibn Kiai Mas Mansur. Beliau mengalami berbagai macam siksaan yang sangat kejam selama di sel tahanan.

Adapun Kyai Mas Ahmad Marzuqi ayahnya, berasal dari bangsawan Astatinggi Sumenep adalah Imam dan khatib tetap di masjid Sunan Ampel, jabatan tertinggi dan prestisius di kalangan santri. Nyai Raudhah, Ibunya dari keluarga kaya raya di pesantren Sidoresmo (nDresmo). Kyai Mas Mansoer memiliki akar tradisi pesantren yang sangat kuat baik dari garis ayah atau ibu. Lahir pada keluarga kaya, bernashab bangsawan di lingkungan pesantren. Mas Mansoer kecil diperintah belajar pada berbagai pesantren dan guru, mulai dari ayahnya sendiri, kemudian Kyai Muhammad Thaha Ndresmo berlanjut ke pesantren Demangan Bangkalan, belajar pada Kyai Khalil yang penuh karamah mendalami al-Quran dan Kitab Alfiyah Ibnu Malik. Namun hanya dua tahun belajar di pesantren Demangan, 
Kyai Khalil yang karismatik dan dikenal waskita karena banyak memproduksi santri yang kelak menjadi tokoh pergerakan di Indonesia itupun wafat.

Mas Mansoer diperintah pergi haji sekaligus mukim dan belajar kepada Kyai Macfudz Termas Pacitan di Mekkah. Empat tahun di Mekkah, Mas Mansoer pindah ke Mesir karena perintah penguasa Arab saat itu, Syarif Husein meski ayahnya tidak bersetuju. Di Mesir ia mengenal dan berguru kepada pejuang nasionalis Syaikh Ibnu Masykawaih. Dari gurunya iniah Mas Mansoer mulai mengenal pergerakan Islam melawan penjajahan dengan konsep (hubbul wathan minal iman) yang menjadi gerakan para santri saat itu. (Departemen Sosial RI, 2008). Sepulang dari Mesir melakukan banyak aktiftas baik di pesantren juga politik pergerakan. Kyai Mas Mansoer mewarisi tradisi pesantren yang kuat, beliau mengasuh dan mengajar di Pesantren An-Najjiyah di Sidoresmo. Akrab dengan kitab kuning dan tradisi pesantren lainnya. Beliau juga seorang jurnalis yang produktif menulis di berbagai media dan penulis beberapa buku. Mendirikan pusat kajian Tasfirul Afkar bersama Kyai Wahab Haabullah meski kemudian keluar karena perbedaan. Hasyim (2015).

Pada pendudukan Jepang Kyai Mas Mansoer menolak budaya (seikkereiameterasu) dengan cara membungkuk ke arah matahari saat terbit. Karena penolakan-nya itu Kyai Mas Mansoer dibui di Kalisosok bersama karibnya Kyai Hasyim Asy'ari. Dalam satu sel di kamar berbeda. Tradisi santri Kyai Mas Mansoer begitu kuat, (Sutresno Kutoyo, Kyai Mas Mansoer 1981), baik dalam cara belajar dan berpikir. Pun dengan model pembelajaran yang beliau lakukan. Pada saat beliau menjadi Ketua Pengurus Besar Muhammadiyah pun beliau manfaatkan dengan membenahi sekolah Mu'alimin dan Mu'alimat Jogjakarta di mana beliau mengasuh. Para pimpinan Muhammadiyah awal dihuni oleh banyak santri didikan pesantren, tapi sayang warga Muhammadiyah kurang perhatian dengan pesantren. Silaturahim pun putus. Bersyukur bisa bertemu dengan dzuriyah Kyai Mas Mansoer Dderesmo.

\section{Modern-Klasik: Memahami Muhammadiyah dalam Kesahajaan}

Masih hangat di ingatan, sikap Pak AR (Abdul Razaq Fakhrudin) terhadap Pancasila sebagai satu-satunya azas-Kesan saya waktu itu, Pak AR terkesan lamban bergerak, tidak cepat merespon seperti ormas-ormas lain, tidak populer dan jarang masuk media. Sama sekali tidak menggambarkan sebagai ketua ormas modern dan progresif. Pada Pilpres kemarin seakan semua berulang 
Pak Haidar pun dianggap kurang berpihak-dianggapnya hanya amar ma `ruf tapi kurang nahy munkar-nya. Tak sedikit pula kader-kader kecewa dan memuji-muji ulama atau imam sebelah-ini soal klasik. Dalam keterasingan itu berbagai pertanyaan dan rasa penasaran mengemuka. Kenapa tidak begini kenapa tidak begitu-Kurang kenceng takbirnya-kurang militan pengikutnyadan kurang tinggi celananya.

Lantas saya membandingkan dengan ulama salafi yang tegas dan lincah, meski tidak pernah punya panitia tapi punya masjid banyak-dengan NU yang banyak pengikut dan berjaya di bidang politik-dengan FPI yang militan dan kencang saat bertakbir atau dengan HTI yang gemuruh demo di jalan jalan dengan bendera tauhid. Tidak jarang kemudian ada banyak jamaah persyarikatan yang tergiur dan pindah haluan. Tapi Muhammadiyah bukan 'Perkoempoelan' macam begitu. Saya menyebutnya Modern-klasik. Ibarat lagu-Muhammadiyah adalah Mozart atau Beethoven-bukan lagu picisan yang riuh dan populair tapi sesaat. Muhammadiyah tidak berbatas ruang apalagi waktu.

Amar ma'ruf dan nahy munkar dipasangkan bukan dipertentangkan-tidak dominan salah satu tapi mengambil sikap tengahan atau moderasi. Dalam berpolitik tidak semuanya berada di dalam juga tidak mengambil posisi di luar berhadapan-semata untuk menjaga amar ma'ruf dan nahy munkar berjalan seimbang. Sikap yang dipilih PP ini kadang tidak populer bahkan di kalangan jamaah sendiri pun sulit dipahami-sebagian menganggap dominan amar ma'ruf-nya atau sebaliknya. Meski belakangan banyak yang membenarkanYang lazim di Muhammadiyah adalah sikap kompromi-yang kemudian dilembagakan dalam Majelis Tarjih. Putusan diambil dari berbagai pilihan kemudian diambil yang terbaik dengan tidak menafikan yang tidak dijadikan pilihan. Baik dalam putusan-putusan pengambilan hukum yang berkaitan dengan aqidah-fiqh dan muamalah. Gaya kompromi ini demikian populer di kalangan ulama ulama Muhammadiyah. Jadi jangan harap ada putusanputusan atau pernyataam ekstrim-sebab semua diputuskan secara kolektif kolegial.

Amal saleh Muhammadiyah tidak bisa hanya dipaku pada amal usaha tapi juga amal pikiran inovatif-Syamsul Arifin, Republika 2019, mengawal modernitas dan menginspirasi banyak orang-bahkan bukan tidak mungkin amal saleh ini jauh melampaui dari amal usahanya yang berupa pendidikan, rumah sakit, bait amal dan lainnya. Maka membatasi amal saleh Muhammadiyah 
hanya pada amal usaha adalah pengkerdilan-amal saleh kita jauh melampaui dari yang terdaftar dan kasat mata. Gagasan brilian para ulama dan foundhing father kita banyak menjadi rujukan.

Sebut saja gagasan sekolah satu atap yang mengajarkan antara ilmu umum dan ilmu agama menjadi model pendidikan nasional, Panglima Besar Jenderal Sudirman bapak ABRI Modern adalah aktifis Hizbul Wathan. Yang paling mutaakhir adalah gerakan moderasi atau wasathiyah. Bukan hanya itu-gerakan purifikasi kembali kepada al Qur'an dan as-Sunnah-dijadikan model dakwah yang simpel dan efisien oleh banyak harakah setelahnya. Ada puluhan Perguruan Tinggi, sekolah, rumah sakit dan bait amal menjadi model yang menginspirasi. Prof Din seperti meneguhkan pendapat Prof Nakamurabahwa Muhammadiyah adalah federasi pemikiran atau konsorsium gagasandari situlah semua berawal dan tumbuh-Muhammadiyah tidak mencukupkan hanya pada romantisme masa salaf seperti yang diagungkan kelompok Salafi atau loyalitas pada imam dan militansi jamaah seperti yang dipraktikkan FPI dan HTI. Karena Muhammadiyah sudah melampaui semua itu —bukan Muhammadiyah yang terasing tapi saya yang kerap kurang bersabar dan jernih bisa memahami pikiran para ulama-ulama di Persyarikatan

\section{Muhammadiyah dan Hal-hal yang Belum Selesai}

Tak elok berlaku sok penting dengan menyoal Pancasila dan UUD 45 sebagai falsafah dan dasar negara, hanya agar terlihat keren dan berjasa. Bukan berarti tak heroik jika berhenti menyoal tentang ideologi negara sebagai philosopphische grounslach atau weltstanchaung. Bagi Muhammadiyah, Pancasila itu sudah selesai-UUD 45 juga sudah final sebagai dasar negara-Muhammadiyah menyebutnya: Daarul Ahdy wa-Syahadah.

Ihwal apakah negara berbentuk Republik atau Kerajaan atau Kesultanan atau Monarkhi atau Khilafah. Dipilih lewat lembaga Syura ijtima ulama atau Sidang Umum Majlis atau dipilih langsung one man one vote sudah tak urgen lagi. Karena sudah selesai dibahas pada eranya Ki Bagus Hadikoesoemo dan KH Wahid Hasyim dan para foundhing father bangsa 79 tahun lalu. Lantas apa yang belum selesai? Pekerjaan selanjutnya adalah membangun bangsa. Menuju cita-cita mulia: negara baldatun thayibah wa rabbun ghafur. Menuju masyarakat Islam yang utama yang diridhai. Cita-cita inilah yang tak pernah selesai dan akan terus menjadi amanah pada setiap generasi tanpa memandang status 
sosial, ras, suku, bahasa, agama, manhaj atau ideologi. Semua berkewajiban sama.

Berpandang demikian maka Muhammadiyah mengambil jalan hikmah bagi maslahat berbasis ke-Islaman, keumatan, kebangsaan, dan ke-Indonesia-an. Ini pekerjaan prinsip yang harus terus menerus ditunaikan. Yang kemudian populer dengan istilah 'mengisi kemerdekaan'. Setelah Pancasila dan UUD 45 tunai dibahas dan disepakati. Maka tak perlu dan tak penting lagi upaya menghadapkan Pancasila dan agama sebagai sesuatu yang berlawanan atau mempertentangkan dengan atribut dan simbol-simbol ke-agama-an yang kontra produktif, (Haidar Nashir: 2017). Sejak awal dirumuskan oleh para ulama dan foundhing father saat itu, Pancasila dan UUD 45 sudah sesuai dengan ajaran syariat Islam dan semua agama bahkan adat dan tradisi kepercayaan yang hidup di Indonesia.

Nilai-nilai universal itulah yang kemudian diangkat dan dibangun sebagai sebuah philosopische groundslagh. Menyoal Pancasila sebagai ideologi dan bentuk negara hanyalah kontra produktif-menyuburkan konflik dan melahirkan perpecahan. Muhammadiyah mengambil bagian dalam mencerdaskan bangsa dengan membangun ribuan sekolah dari PAUD hingga universitas. Membangun ribuan masjid, pesantren adalah ikhtiar membangun masyarakat yang berketuhanan yang religius. Dan lembaga-lembaga berbasis filantropi lainnya untuk meningkatkan kesejahteraan, keadilan sosial di tengah masyarakat, menciptakan perdamaian, persatuan, toleransi dan membangun peradaban yang humanis-inilah pekerjaanpekerjaan besar yang belum selesai. Inilah manhaj Muhammadiyah dalam berpolitik berbasis kebangsaan dan keumatan, bukan berebut kekuasaan.

Pak AR Fachruddin (1990) dalam buku Tanya Jawab Entheng Enthengan, Muhammadiyah menjadi bagian penting dan menempatkan diri sebagai faktor penentu dan untuk tetap menjaga spirit kebangsaan, keumatan dan ke-Islaman. Koneksi ini harus diperkuat dan tak boleh putus-para ulama dan pimpinan Muhammadiyah secara institusional dan personal adalah pendiri negaraitulah ikhtiar menegakkan syariat yang terus diperjuangkan tanpa gaduh. Muhammadiyah sebangun dengan negara--Muhammadiyah secara institusional tidak pernah berhadap-hadapan apalagi mengambil sikap oposisi terhadap negara tapi sebagai mitra kritis yang konstruktif sebagai manifestasi amar ma'ruf nahy munkar.

Selamat bermuktamar! 


\section{Daftar Pustaka}

Alfian. (1989). Muhammadiyah: The Political Behavior of a Muslim Modernist Organization Under Dutch Colonialism. Yogyakarta: Gajah Mada University Press.

Boy, P. (2016). Membangun Relasi Teks-Konteks : Keimanan dan Pencarian Bentuk Masyarakat Ideal. Jurnal Bestari, 35, 113-120.

Departemen Sosial RI. (2008). Wajah dan perjuangan pahlawan nasional. Jakarta: Departemen Sosial RI.

Fachruddin, A., \& Yogya. (1990). Tanya-jawab entheng-enthengan. Yogyakarta: Pustaka SM.

Fitri, A. Z. (2015). PENDIDIKAN ISLAM WASATHIYAH: MELAWAN ARUS PEMIKIRAN TAKFIRI DI NUSANTARA. Kuriositas: Media Komunikasi Sosial Dan Keagamaan.

Fong, P. E., \& Haggard, S. (1992). Pathways from the Periphery: The Politics of Growth in the Newly Industrializing Countries. Pacific Affairs. https:// doi.org/10.2307/2760072

Haikal, H. (1993). beberapa percikan mas mansur (1916-1946). Islamiyyat, 14, 65-76.

Hasyim, Mustofa, W. (2015). Ensiklopedi Muhammadiyah: sejarah, tokoh, dan pemikiran. Yogyakarta: Majelis Ekonomi Kewirausahaan, Pimpinan Wilayah Muhammadiyah DIY, Lembaga Pengembangan Pendidikan, Penelitian dan Masyarakat UMY, dan MataBangsa.

Ilyas, Y., Amin, Masyhur, M., \& Lalito, Daru, M. (1993). Muhammadiyah dan NU: reorientasi wawasan keIslaman. Yogyakarta: LPPI UM, LKPSM NU dan PP Al-Muhsin.

Jainuri, A. (2004). Orientasi Ideologi Gerakan Islam. Surabaya: LPAM.

Jinan, M. (2015). Muhammadiyah Studies: Transformasi Kajian tentang Gerakan Islam di Indonesia. Analisa Journal of Social Science and Religion. https://doi.org/10.18784/analisa.v22i2.96

Kraar, L. (1988). The New Powers of Asia. Reade's Dogest, 52(309), 44.

Nashir, H. (2016). Muhammadiyah Gerakan Pembaruan. Yogyakarta: Suara Muhammadiyah.

Ni'mah, Z. A. (2014). Pemikiran Pendidikan Islam Perspektif KH AHMAD 
DAHLAN ( 1869-1923 M ) DAN KH HASYIM AS'ARI (1871-1947) Study Komparatif dalam Konsep Pembaruan Pendidikan Islam di Indonesia. Didaktika Religia.

Sajad, A. (2010). Menziarahi Batu Nisan Tajdid: Refleksi Jelang Seabad Muhammadiyah. In T. Hidayat \& I. Hasanuddin (Eds.), Satu Abad Muhammadiyah Mengkaji Ulang Arah Pembaruan (pp. 185-196). Jakarta Selatan: Paramadina.

SOHARI, S. (2013). ETOS KERJA DALAM PERSPEKTIF ISLAM. ISLAMICONOMIC: Jurnal Ekonomi Islam. https://doi.org/10.32678/ ijei.v4i2.16

Thaib, E. J. (2014). Al-Qur'an Dan As-Sunnah Sebagai Sumber Inspirasi Etos Kerja Islami. Jurnal Dakwah Tabligh. 